\title{
MÉdIA E MIGRAÇÕES FORÇADAS: REPRESENTAÇÕES SOCIAIS DOS REFUGIADOS NOS MÉDIA PORTUGUESES EM DOIS MOMENTOS MEDIÁTICOS (2015 E 2019)
}

\author{
Dora Santos-Silva \\ Instituto de Comunicação da Nova (ICNOVA), Faculdade de Ciências \\ Sociais e Humanas, Universidade Nova de Lisboa, Portugal \\ Débora Guerreiro \\ Faculdade de Ciências Sociais e Humanas, Universidade Nova de Lisboa, Portugal
}

\begin{abstract}
Resumo
Os movimentos migratórios forçados marcaram a agenda económica, política e social em 2015 e, nessa sequência, a dos média, que assumiram um papel essencial na representação social dos refugiados. Em 2019, assistimos a um novo momento mediático, motivado pelas dificuldades encontradas pelos navios humanitários em atracar nos portos europeus. O objetivo deste artigo foi analisar a forma como os média portugueses cobriram a temática das migrações forçadas em dois momentos mediaticamente relevantes, em 2015 e em 2019, e de que forma contribuíram para a representação social dos refugiados. A partir de uma análise de conteúdo, concluímos que os jornais analisados subvalorizaram os refugiados enquanto indivíduos com identidade própria, reduzindo-os a um grupo homogéneo e sem voz. Esta tendência, já presente em 2015, acentuou-se em 2019 com a ausência de artigos explicativos, com a predominância de uma visão ocidental e uma dependência das agências de notícias.
\end{abstract}

\section{MEDIA AND FORCED MIGRATIONS: SOCIAL RePresentations of Refugees in the Portuguese MEDIA IN TWO MEDIATIC PEAKS (2015 AND 2019)}

\begin{abstract}
Forced migration movements marked the economic, political, and social agenda in 2015. Consequently, these events also determined the agenda of the media, which took on an essential role in the social representation of refugees. In 2019, when humanitarian ships found it hard to dock at European ports, we saw another peak in media coverage. The purpose of this article is to analyse how the Portuguese media covered the theme of forced migration during two of the most relevant moments (2015 and 2019) and thus, how they contributed to the social representation of refugees. After a content analysis, we concluded that the newspapers on which our study focused undervalued refugees as individuals with their own identity, reducing them to a homogeneous and voiceless group. This trend, already present in 2015, was further emphasised in 2019 . There was a clear absence of explanatory articles, with the media output showing a predominance of western perspective and a constant reliance on news agencies as sources.
\end{abstract}




\section{INTRODUÇÃO}

Em 2015, a Europa assistiu à desde então designada "crise dos refugiados no Mediterrâneo" quando, nesse ano, cerca de um milhão de pessoas alcançaram a costa europeia por mar, deixando nas suas águas 3.700 pessoas que aí pereceram. O fluxo de refugiados, considerado o maior desde a II Guerra Mundial, teve como protagonistas cidadãos sírios, afegãos, iraquianos, eritreus, entre outros, que se deslocaram forçadamente devido a conflitos armados.

Segundo o relatório do Alto Comissário das Nações Unidas para os Refugiados (ACNUR, 2019), existiam no mundo, em 2018, 25,9 milhões de refugiados, 41,3 milhões de pessoas deslocadas internamente e 3,5 milhões requerentes de asilo, devido a cenários de conflito e violência. A República Árabe da Síria liderava, com 6,1 milhões de pessoas deslocadas, seguida da Colômbia (5,9 milhões) e da República Democrática do Congo ( 3,1 milhões). A Síria era também o país com maior número de refugiados no mundo: 6,7 milhões.

Desde o começo da crise, em 2013, já morreram mais de 10 mil pessoas no Mediterrâneo, segundo a Organização Internacional para as Migrações (OIM, 2019), das quais 500 no primeiro semestre de 2019. Se, em 2015, pico da crise migratória, tinham chegado mais de um milhão de pessoas às costas europeias, só nos primeiros três dias de 2019, outro momento relevante, eram resgatados 400 migrantes pela Guarda Fronteira Espanhola (Chaíça, 2019).

Entre 2015 e 2019, muito mudou no panorama social e político europeu: a surpresa e a corrente de solidariedade inicial deram lugar ao medo nos países recetores, aumentou a força política dos partidos anti-imigração e foram celebrados acordos de retenção de refugiados ao nível internacional. Em junho de 2019, a Itália, um dos três países que mais migrantes tinham recebido em 2018 (Espanha em primeiro lugar, seguida da Grécia), fechava todos os portos aos navios de ajuda humanitária que trouxessem migrantes (Fernandes, 2019).

Neste contexto, Portugal assumiu, desde o início da crise, a sua disponibilidade para receber refugiados, facto que aumenta a responsabilidade da cobertura jornalística portuguesa em desconstruir estereótipos relacionados com os refugiados e prestar uma informação clara e aprofundada.

Embora seja uma problemática antiga, existem três características desta sociedade que revestem a crise migratória de novos contornos, elencados por Abdo, Cabecinhas e Brites (2019): a globalização, na qual estes processos "se tornam mais intensos, velosos e abundantes" (p. 80); o papel dos média, que acompanham essa "velocidade, abundância e intensidade" (p. 80); e a própria sede que a sociedade tem do espetáculo, alimentado pelos média.

Neste artigo, partimos da hipótese já comprovada por vários autores (como Blumell, Bunce, Cooper \& McDowell, 2020; Chouliaraki \& Stolic, 2017; Empinotti, 2017; 
Gemi, Ulasiuk \& Triandafyllidou, 2013; Guerreiro, 2018; Mclntyre, 2013; Silvestre, 2011) de que os média influenciam a perceção da sociedade em relação à problemática dos migrantes e refugiados e que são os principais intermediários numa relação com o outro que só existe muitas vezes nesse plano. Nessa lógica, os média têm um papel essencial na construção do imaginário coletivo sobre refugiados e crise migratória.

Este estudo tem como objetivo analisar a forma como dois jornais portugueses cobriram a temática dos refugiados em dois momentos mediaticamente relevantes: um de 2015 - período em que deu à costa de uma praia turca um menino sírio sem vida - e outro de 2019, marcado pelas dificuldades encontradas pelos navios humanitários em atracar nos portos europeus. Pretende explorar em particular qual é a representação social dos refugiados, a partir da análise de características editoriais das peças jornalísticas publicadas e de uma tipologia de regimes de visibilidade proposta por Chouliaraki e Stolic (2017). Para alcançar este objetivo, foram delineadas três perguntas de investigação (PI):

$\mathrm{PI}_{1}$ quais são as principais características editoriais das peças publicadas em dois jornais portugueses sobre a temática dos refugiados, em dois momentos mediaticamente relevantes de 2015 e 2019?

$\mathrm{Pl}$ 2: que representações sociais são feitas dos refugiados, a partir dessas características editoriais e das imagens adotadas pelos jornais como estratégia de visibilidade?

$\mathrm{Pl}_{3}$ : quais são as principais diferenças entre a cobertura jornalística de 2015 e de 2019 ?

Para responder a estas questões, foi utilizada uma metodologia comparativa baseada na análise de conteúdo de duas semanas, em 2015 (02 a 08 de setembro) e em 2019 (30 de junho a 07 de julho), em dois jornais diários online de referência - Público e Observador.

\section{ENQUADRAMENTO TEÓRICO}

\section{ProcesSOS MIGRATÓRIOS FORÇADOS E A RESPONSABILIDADE DOS MÉDIA}

O ponto de partida para a reflexão entre refugiados e média é a própria definição de refugiado que se encontra na Convenção de Genebra de 1951, alterada pelo Protocolo de 1967, que veio alargar o seu âmbito. No mesmo ano, é criado o Alto Comissariado das Nações Unidas para os Refugiados (ACNUR).

Os refugiados fazem parte de um conjunto amplo que se designa por "migrantes forçados", que incluem também outras categorias como os requerentes de asilo. O direito a requerer asilo está consagrado no art. $14 .^{\circ}$ da Declaração Universal dos Direitos Humanos (ONU, 1948). A pessoa pode pedir asilo ou solicitar o estatuto de refugiado, de acordo com as respetivas condições.

Considera-se refugiado a

pessoa, que, receando com razão ser perseguida em virtude das sua raça, religião, nacionalidade, filiação em certo grupo social ou das suas opiniões políticas, se encontre fora do país de que tem a nacionalidade e que não possa ou, em virtude daquele receio, não queira pedir a proteção daquele país. (ONU, 1951) 
A liberdade de expressão também é um direito humano plasmado na Declaração Universal dos Direitos Humanos, para a qual o jornalismo assume um papel de relevo, desde logo porque o seu propósito "é fornecer aos cidadãos a informação de que precisam para serem livres e se autogovernarem" (Kovach \& Rosenstiel, 2001, p. 16).

Mesmo no novo ecossistema digital, os média determinam a agenda do mundo e atuam ainda como únicos intermediários em vários acontecimentos mundiais, tendo o poder de alargar os horizontes do público ou de os restringir (Pöyhtäri, 2014). No caso dos refugiados, essa evidência é maior, dado que a população não os conhece e, portanto, constrói a sua perceção a partir das representações dos média.

Com o aumento do discurso anti-imigração, bem como da projeção dos partidos anti-imigração em vários países europeus, a cobertura deste tema assume cada vez mais relevância, até porque o jornalismo tem a capacidade de habilitar as audiências a desenvolver um verdadeiro conhecimento global (Hafez, 2009).

O jornalismo tem, assim, a responsabilidade acrescida de cobrir um tema que é sobretudo de direitos humanos. Thompson (2007) sugere a existência de uma responsabilidade para reportar, que se interliga com uma responsabilidade moral em relação aos direitos humanos. Esta não é uma opinião isolada: Rose (2013) defende o conceito de human rights-based aproach, baseado no princípio de que a abordagem aos direitos humanos deve ser uma função fundamental nas obrigações de um jornalista, obrigando- o a identificar a violação e a incluir nas suas reportagens formas de eliminar o abuso. Também Shaw (2012) afirma que se o público tiver um maior entendimento dos problemas através da sua explicação é mais provável ter empatia com o sofrimento das pessoas e apelar à intervenção internacional, ajudando a superar a falta de memória histórica que constitui um obstáculo ao entendimento (The International Council Human Rights Policy, 2002).

\section{REPRESENTAÇÕES SOCIAIS DOS REFUGIADOS NOS MÉDIA}

A teoria das representações sociais só entrou na agenda científica na segunda metade do século XX, pela mão do psicólogo social Serge Moscovici (1961), influenciado pelas bases teóricas que Durkheim tinha lançado no século XIX. O objetivo desta teoria era explicar fenómenos a partir de uma perspetiva coletiva, isto é, as representações sociais correspondem a crenças ou ideias que temos relativamente a uma pessoa, a uma comunidade, a um acontecimento ou objeto, fruto da nossa interação social. Além de Moscovici, o conceito de representações sociais foi trabalhado por Denise Jodelet (1989), outra referência na área, que as definiu como "uma forma de conhecimento, socialmente elaborado e compartilhado, que tem um objetivo prático e concorre para a realidade comum a um conjunto social" (p. 36).

A académica francesa salienta duas características desta forma de conhecimento que são cruciais para pensarmos a relação entre os média e as representações sociais dos refugiados: a "construção", isto é, a representação social é uma construção que deriva da relação entre um sujeito e o objeto; e a "expressão", isto é, deriva dessa relação uma interpretação. 
Se aplicarmos isto ao contexto deste artigo, podemos concluir que a representação social do refugiado é fruto de uma construção que resulta da relação entre a população e o refugiado, relação essa possibilitada pelos média, pelo que a cobertura jornalística determina a interpretação que a população tem desta crise e do refugiado como o outro. Os média influenciam a opinião pública e contribuem para o grau de aceitação e compreensão do refugiado.

Partindo deste raciocínio, é essencial trazer para a discussão investigações académicas que já se tenham debruçado sobre a análise da cobertura jornalística dos refugiados e das suas representações sociais.

\section{QUEM É O REFUGIADO NOS MÉDIA?}

Já em 2003, Peter Mclntyre defendia que os refugiados eram historicamente despersonalizados pelos média e representados como um grupo a ser temido e rejeitado, na obra Human rights reporting - a handbook for journalists in South-eastern Europe, publicado pela Federação Internacional dos Jornalistas. Um estudo do Observatório da Comunicação sobre a cobertura dos imigrantes e das minorias étnicas pelos média portugueses em 2001 e 2002 também concluía que estes grupos estavam associados sobretudo a notícias sobre delitos (OberCom, 2003). Ao longo do século XXI esta realidade foi sendo comprovada por diversos estudos académicos.

Gemi, Ulasiuk e Triandafyllidou (2013) analisaram o impacto dos valores-notícia, das fontes e da agenda nas notícias relacionadas com processos migratórios em média de seis países europeus e concluíram que têm uma linha editorial desequilibrada relativa à cobertura da migração, nomeadamente aos acontecimentos que selecionam (os negativos) e as fontes que usam, o que pode provocar uma perceção deturpada no público.

Por sua vez, o estudo de Blumell et al. (2020), com base na cobertura de média online do Reino Unido, mostra que há uma sobrevalorização da criminalidade cometida pelos requerentes de asilo e uma politização deste tema: os média considerados de esquerda focam-se na vitimização, enquanto os de direita, na criminalidade. Os autores apontam a necessidade de mais soft news sobre refugiados, e não apenas hard news, para dar mais contexto, personalização e esclarecimento ao tema.

Para além da falta de voz e de uma participação ativa, os refugiados são, ainda, representados visualmente como grupos e não como indivíduos, como confirmam estudos de base semiótica. Investigadoras do Reino Unido analisaram imagens publicadas por órgãos de comunicação social de cinco países europeus sobre refugiados entre junho e dezembro de 2015 e concluíram que "falham na humanização de migrantes e refugiados" (Chouliaraki \& Stolic, 2017, p. 1162) e que urge "mudar radicalmente a forma como entendemos a responsabilidade dos media para com os outros vulneráveis" (p. 1162).

Estas autoras propuseram uma tipologia de regimes de visibilidade da crise, a partir da qual reconstroem visualidades específicas dos refugiados. Identificaram cinco configurações visuais básicas: vida biológica, empatia, ameaça, hospitalidade e auto-reflexão. As imagens escolhidas pelos órgãos de comunicação social são depois enquadradas numa ou mais destas variáveis de análise. 


\section{VISIBILIDADE COMO VIDA BIOLÓGICA}

Nesta variável, as investigadoras incluem imagens que representam os refugiados como uma "massa de desafortunados" (p. 1167), ou seja, desprovidos de identidade e voz, à mercê da benevolência ocidental. São imagens que promovem um distanciamento social e que não oferecem qualquer contexto sobre o sofrimento dos refugiados ou dos motivos da sua migração forçada.

\section{VISIBILIDADE COMO EMPATIA}

O regime de visibilidade como empatia é associado à humanização das imagens, como uma criança que chora, uma mãe com o seu filho ao colo. Ao contrário do primeiro regime, neste há uma perspetiva visual mais próxima e uma tentativa de individualizar os refugiados, fomentando a compaixão e a caridade.

\section{VISIBILIDADE COMO AMEAÇA}

As investigadoras incluem neste regime imagens de jovens armados ou barcos a tentar atracar em portos europeus, que acabam por suscitar medo nos leitores ou a sensação de ameaça à segurança. É, por isso, uma "vilificação daqueles que não são como "nós'” (p. 1169).

\section{VISIBILIDADE COMO HOSPITALIDADE}

Este regime de visibilidade é associado a ativismo político, como imagens de manifestações pró-refugiados, mensagens de acolhimento por parte da população ou outros atos de hospitalidade. Embora sejam, à partida, positivas, acabam por subjetivar os refugiados.

\section{VISIBILIDADE COMO AUTO-REFLEX̃̃O}

Este último regime de visibilidade é associado à identificação dos refugiados como parte de nós e não os "outros" (como imagens de celebridades a ajudar os refugiados, gráficos ou imagens de destroços, sem personagens).

Este mapeamento dos regimes de visibilidade pública torna os refugiados "objetos da 'nossa' responsabilidade" (p. 1172), segundo Chouliaraki e Stolic, e acabam por ser "espaços-chave de moralização que produzem e regulam as disposições do público" (p. 1172 ) em relação aos refugiados, perpetuando um distanciamento ou contribuindo para uma responsabilização coletiva. As investigadoras concluem que esta crise humanitária é, na essência, uma crise da noção de responsabilidade para a qual a representação imagética dos refugiados contribui em grande parte.

Em Portugal, a cobertura jornalística dos refugiados também tem sido objeto de vários estudos. Uma tese de mestrado sobre as representações dos refugiados e requerentes de asilo nos média portugueses (Silvestre, 2011) concluiu que estes são 
sistematicamente desqualificados enquanto fonte de informação credível e a sua voz é silenciada. Outra tese de mestrado defendida em 2018, que se debruçou sobre a cobertura jornalística portuguesa da crise dos refugiados em 2015, concluiu que houve falhas ao nível da explicação e contextualização das peças, a começar pela definição correta de refugiado, e que há necessidade de um maior comprometimento e especialização dos jornalistas para com os direitos humanos (Guerreiro, 2018).

Outro estudo com base em imagens publicadas em 2015 no jornal diário português Público mostra que há poucas pistas sobre a identidade dos refugiados, representados recorrentemente como grupos homogéneos e não indivíduos (Empinotti, 2017). A autora alerta para o facto de serem repetidos esquemas de representação "que tendem a reduzir a compreensão do refugiado como alguém em constante deslocamento, muitas vezes em situação de risco ou más condições" (p. 114).

A literatura portuguesa diz-nos que nestes encontros com os refugiados, mediados pelos média, estes indivíduos são representados como os outros, sem voz, sem identidade, sem contexto, sem memória. Moisés Lemos Martins (2019) vai mais longe e qualifica esta relação com o outro: "e se o que está em causa é ignorar o outro, ou então, segregá-lo, discriminá-lo e dominá-lo, do que se trata mesmo é de exercer sobre ele uma violência" (p. 21).

\section{OBJETO DE INVESTIGAÇÃo E METODOLOGIA}

A 02 de setembro de 2015, Alan Kurdi, uma criança síria de três anos, deu à costa sem vida numa praia turca. A família fazia a travessia do mar Egeu, da Turquia para a Grécia, de barco. A mãe e o irmão também perderam a vida. A fotografia, captada por Nilüfer Demir, redefiniu a crise dos refugiados - ganhou a legenda de "naufrágio da humanidade" - e levou a um pico da cobertura jornalística sobre a temática.

Os primeiros dias de julho de 2019 foram marcados pelas dificuldades encontradas pelos navios humanitários em atracar nos portos europeus com migrantes a bordo. No dia quatro, uma embarcação que transportava migrantes capotava ao largo da Tunísia, provocando a morte a 82 pessoas. $\mathrm{O}$ acontecimento mais mediático foi protagonizado pela capitã do navio Sea Watch que atracou em Lampedusa, contra a ordens da polícia italiana.

Nesse sentido, este estudo tem como objetivo analisar a forma como os média portugueses cobriram a temática dos refugiados em dois momentos mediaticamente relevantes: em 2015 (02 a o8 de setembro) e em 2019 (30 de junho a 7 de julho). Houve outros momentos igualmente relevantes, mas o de 2015 foi o primeiro caso que despoletou uma cobertura jornalística à escala global e a consternação da opinião pública; o de 2019 foi escolhido por ser o mais recente à data deste estudo.

O artigo pretende explorar em particular qual é a representação social dos refugiados, a partir da análise de características editoriais das peças jornalísticas publicadas e de uma tipologia de regimes de visibilidade proposta por Chouliaraki e Stolic (2017). Para alcançar este objetivo, foram delineadas três perguntas de investigação: 
PIı: quais são as principais características editoriais das peças publicadas em dois jornais portugueses sobre a temática dos refugiados, em dois momentos mediaticamente relevantes de 2015 e 2019?

$\mathrm{Pl}_{2}$ : que representações sociais são feitas dos refugiados, a partir dessas características editoriais e das imagens adotadas pelos jornais como estratégia de visibilidade?

PI3: quais são as principais diferenças entre a cobertura jornalística de 2015 e de 2019?

Para responder a estas questões, foi utilizada uma metodologia comparativa baseada na análise de conteúdo das semanas supramencionadas, em dois diários online de referência - Público e Observador. À data de 2015, estes dois diários tinham, no campo dos jornais de referência, os maiores números de páginas visualizadas. Em 2019, foi mantido o corpus para sustentar a análise comparativa. Não foi objetivo deste artigo fazer uma análise da evolução da cobertura jornalística portuguesa entre 2015 e 2019 (período durante o qual houve vários outros momentos mediaticamente relevantes), mas, sim, fazer uma comparação entre momentos com uma diferença de quatro anos, de forma a identificar diferenças nas estratégias editoriais.

O levantamento das peças jornalísticas foi feito através das palavras-chave "refugiado" e "migrante" (em 2019, houve uma mudança de nomenclatura dos refugiados) reforçado com o levantamento direto das peças alocadas ao tópico e áreas específicas definidos pelo Público e pelo Observador. A análise teve em conta variáveis, como o género jornalístico, o autor, as fontes, o tópico, o ângulo de abordagem, o uso de imagem, a sua proveniência e enquadramento.

A análise de conteúdo foi complementada por uma análise mais detalhada das imagens usadas - não querendo chegar a uma análise multimodal - com base na tipologia de visibilidade proposta por Chouliaraki e Stolic (2017), de forma a percebermos o papel que as imagens têm nas representações sociais dos refugiados através das suas configurações visuais. Essa tipologia foi já apresentada no enquadramento teórico e integra a visibilidade como vida biológica, empatia, ameaça, acolhimento/hospitalidade e auto-reflexão.

\section{APRESENTAÇÃo E DisCUSSÃo doS RESUlTAdOS \\ MENOS PEÇAS E MENOS MEMÓRIA}

Com base na análise de conteúdo a dois diários generalistas online - Observador e Público - num período distinto de 2015 (02 a 08 de setembro) e de 2019 (30 de junho a o7 de julho), foram identificadas 145 peças em 2015 (88 no Observador e 57 no Público) e 48 peças em 2019 (31 peças no Observador e 17 no Público).

Podemos observar, desde logo, uma diminuição significativa do número de peças publicadas nos dois períodos analisados (menos 97). Embora a fotografia do menino sírio, em 2015, tenha suscitado uma ampla cobertura não só nos órgãos de comunicação social, mas também nas redes sociais, o naufrágio da embarcação que levou à morte de 82 migrantes, em 2019, também foi um acontecimento igualmente grave com repercussões políticas e sociais assinaláveis, pelo que, à partida, não haverá explicação rigorosa para justificar esta disparidade na cobertura jornalística. No entanto, os pontos em análise seguintes poderão contribuir para explicar esta diminuição de peças. 
É importante considerar a própria estratégia de navegação nos websites destes órgãos de comunicação social. O Observador tinha, em 2015, uma área intitulada "crise dos refugiados", onde se encontravam todas as peças associadas ao tópico refugiados. Terá tido em consideração a especificidade do assunto e a sua potencial visibilidade ao longo do tempo, servindo também como facilitador de pesquisa. Porém, em 2019, as peças encontram-se dispersas por várias secções do jornal, com tópicos como "mundo", "migrantes", "direitos humanos", "política”, entre outros. Também se verificaram casos de peças mal arquivadas e ainda algumas no tópico "crise dos refugiados" (que não desapareceu completamente, mas deixou de ser um agregador fiável).

Em relação ao Público, a dispersão já se verificava em 2015, mas é interessante constatar que, em 2019, os refugiados só surgem como tópico principal (imediatamente antes do título) em duas peças e em 2015 em oito peças. Mesmo follow-ups do mesmo acontecimento têm tópicos diferentes, o que sugere que ainda não há uma estratégia de organização dos tópicos nos dois websites.

\section{PrevalênCia do “aContecimento" RePlicado Por agênCIAS E O CONTEXTo PORTUGUÊS}

Em 2015, o género jornalístico maioritário foi a notícia, com 89,77\% no Observador e $84,21 \%$ no Público, o que aponta para uma prevalência do acontecimento face à explicação e enquadramento, que poderiam ser verificados em peças mais desenvolvidas. Em 2019, esse domínio foi ainda mais significativo: todas as peças publicadas no $O b$ servador são notícias; no Público, equivalem a 65\% (há uma reportagem, uma crónica e dois artigos de opinião).

A prevalência de notícias também está associada à autoria e à fonte primária. Se, em 2015 , peças assinadas exclusivamente por agências de notícias correspondiam a $23,9 \%$ no Observador e a $8,77 \%$ no Público, em 2019 , esse número sobe para $80,65 \%$ (Lusa) e $41 \%$ (Lusa e Reuters), respetivamente. Mesmo nos artigos assinados por jornalistas, as agências de notícias continuam a ser a fonte prevalente. Esta replicação de conteúdos de agências de notícias diz-nos que, por um lado, não foram investidos recursos nem se aprofundaram os temas, mesmo que saibamos, à partida, que não é fácil chegar à voz dos refugiados. Estes dados podem também ajudar a explicar a diminuição do número de peças em 2019 face a 2015.

Além das agências de notícias, as fontes mais comuns quer no Público quer no Observador, nos dois momentos analisados, são as institucionais: Organização das Nações Unidas (ONU), ACNUR e governos de vários países. Uma vez mais, são as "elites brancas" a serem ouvidas, ainda que as organizações não governamentais (ONG) em causa persigam a defesa dos direitos humanos e o apoio dos refugiados.

Quanto aos protagonistas desta crise, a sua voz é quase ausente. É certo que não é fácil chegar ao contacto com os refugiados, mas mesmo assim esperava-se mais. De facto, em 2019, apenas uma reportagem publicada no Público, mas assinada por uma jornalista da Reuters, tem a voz de refugiados. O mesmo número surge no Observador. 
Relativamente ao uso de cidadãos como fontes, é de salientar que continuam com percentuais menores, como se analisa no Observador, e que a voz mais ouvida foi a da capitã Carola Rackete que, numa altura em que os países europeus recusavam a entrada dos navios humanitários repletos de refugiados, ficou conhecida por ter representado a luta pelo salvamento no mar. O mesmo se verifica no Público. Em 2015, a percentagem era um pouco mais alta: $45,61 \%$ (incluindo os refugiados) no Público e $23,86 \%$ no Observador.

Em 2015, as peças sobre o contexto português na crise dos refugiados correspondiam a $29,55 \%$ no Observador e a $40,35 \%$ no Público. Portugal mostrava-se disponível para acolher refugiados e discutia-se publicamente, entre as entidades políticas e civis, qual seria a melhor forma de recolocação. Já em 2019, o percentual diminuiu para 9,68\% no Observador, o que pode ser explicado pela replicação das notícias de agências, que se centraram nos acontecimentos ocorridos fora de Portugal e sem grande impacto para os decisores nacionais. Já o Público, com menos replicação de conteúdos de agências, obteve $41,18 \%$ de peças em contexto português, onde, ao contrário do Observador, que se focou apenas nos salvamentos de refugiados pela Polícia Marítima portuguesa na Grécia, abordou também a situação do ativista português Miguel Duarte, acusado em Itália de auxílio à imigração ilegal.

\section{QUEM É O REFUGIADO NOS MÉDIA?}

Para responder a esta questão, socorremo-nos não só da análise de conteúdo, mas também de um olhar mais detalhado das imagens publicadas nos dois jornais segundo a tipologia de visibilidade proposta por Chouliaraki e Stolic (2017): vida biológica, empatia, ameaça, acolhimento/hospitalidade e auto-reflexão.

Contudo, começando pelo princípio, é condição necessária à compreensão do outro saber quem é o outro. Saber quem é o refugiado, partindo da sua definição, permite-nos combater alguns preconceitos e estereótipos relacionados com este grupo.

Porém, a definição de refugiado "pessoa que receia ser perseguida em virtude da sua raça, religião, nacionalidade, grupo social ou das suas opiniões políticas e que não pode pedir proteção ao seu país de origem", como está inscrita na Convenção de Genebra de 1951 Relativa ao Estatuto dos Refugiados, apenas pontualmente foi incluída nas peças - uma em 88 no Observador e um em 57 no Público, em 2015. Num tema marcado por grandes divergências de conceitos (à data, mais especificamente, entre o que era um refugiado ou um migrante económico), a definição foi considerada o ponto de partida para a compreensão da crise dos refugiados.

Em 2019, nenhuma peça quer no Público quer no Observador contém a definição de refugiado ou uma aproximação à sua identificação. Além disso, este desconhecimento relativamente ao refugiado é agravado pelo uso aleatório da palavra "migrante". No Observador, na semana analisada, só foi usada duas vezes a palavra "refugiados"; as restantes peças, mesmo sobre o mesmo assunto, foram indexadas ao tópico "migrantes" ou tinham essa palavra no texto, talvez porque este conceito abarque várias realidades, mas que pode abrir caminho a equívocos desnecessários na perceção do leitor (no Público, isto não se verificou). 
Se é certo que a população que foge de conflitos armados e que estava a tentar desembarcar em 2019 dos vários navios humanitários ou barcos clandestinos não tem ainda o estatuto de refugiado (que é obtido no país de acolhimento depois de verificadas várias condições), também não pode ser comparada aos migrantes que deixam os seus países por razões económicas. O uso da expressão "migrante forçado" em vez de apenas "migrante" poderia acautelar alguma desinformação relacionada com a própria identidade dos refugiados.

Contribuem também para o desconhecimento do refugiado o ângulo de abordagem das próprias peças jornalísticas. Em 2015, denotou-se uma primazia da visão ocidental no Observador (90,91\%) e no Público $(87,72 \%)$, isto é, fontes (oficiais e não oficiais) ocidentais que falam sobre o problema como sendo do outro. Inversamente, verificou-se o detrimento da visão intercultural, uma vez que o ponto de vista assumido na cobertura esteve muito mais alinhado com as preocupações ocidentais do que com as preocupações dos "protagonistas" da crise, de cariz multicultural.

Em 2019, o ângulo de abordagem ocidental é ainda mais flagrante, se pensarmos que os heróis das peças são os capitães dos navios humanitários ou os países que acoIhem os refugiados. O herói nunca é o refugiado que conseguiu fugir do seu país - mas também não aparece como vítima.

Esta sub-representação dos refugiados nos textos, sendo muitas vezes reduzidos a números ou a um grupo homogéneo, é ainda agravada pelas imagens escolhidas pelos jornais, numa evolução claramente negativa de 2015 para 2019. Neste ano, em $96,77 \%$ das peças do Observador havia uma única imagem a acompanhar o texto, sem recurso a galerias de imagens, o que se considerou muito pobre numa lógica visual. O Público também só usou galerias de imagens em duas das 17 peças.

Porém, são poucas as imagens publicadas nos jornais que retratam os refugiados como indivíduos com voz e identidade própria. No Público, só em quatro das 17 são protagonistas. Nas restantes, as imagens escolhidas são de políticos ocidentais, chefes de missão de ONG ou capitães dos navios humanitários. No caso do Observador, embora houvesse mais imagens com refugiados, $29,03 \%$ das imagens estavam desatualizadas (os dados apontam para que não sejam de 2019 e sim de anos anteriores), 12,90\% eram padronizadas (por representarem os refugiados de forma indiferenciada, massificada), $22,58 \%$ estavam descontextualizadas (por não terem correspondência com a notícia) e $6,45 \%$ eram repetidas. O mesmo não se verificou com o Público que teve o cuidado, no caso de imagens com refugiados, de ter uma legenda que confirmava a atualidade e a pertinência daquela imagem.

Aplicando os regimes de visibilidade propostos por Chouliaraki e Stolic (2017) às imagens com refugiados, nota-se uma predominância clara de configurações visuais relacionadas com a vida biológica, isto é, prevalecem imagens de pessoas indiferenciadas - ou "massa de desafortunados" (p. 1167) nos barcos, como caracterizam as investigadoras. No caso do Observador, no qual as representações imagéticas de refugiados equivalem a 35,48\% do total, 12,90\% eram situações de homogeneização/generalização (ex. fotos de grupos indiferenciados), enquanto $9,68 \%$ representavam uma massa humana 
despersonalizada, como as "clássicas" imagens de botes com aglomerados de pessoas. Tais imagens tornaram-se incontornáveis na cobertura da crise em 2015, serviram de padrão à situação e continuam a aparecer nos mesmos moldes, por vezes até desatualizadas, conforme os dados anteriormente apresentados. No Público, também surgem as mesmas imagens de refugiados indiferenciados, em barcos ou em situações de destruição. Este regime de visibilidade promove o distanciamento dos leitores e a ausência de responsabilidade coletiva, dado que não há um "rosto" nem uma história.

A segunda tipologia de visibilidade mais utilizada é a ameaça, com o constante uso de imagens de barcos com os refugiados a tentarem sair de forma desesperada. Como referem Chouliaraki e Stolic (2017), este regime de visibilidade promove o receio, o medo e a sensação de insegurança. Se aliarmos este tipo de imagens às da primeira categoria - que promove o desconhecimento - então a ameaça "do desconhecido" e do outro assume proporções ainda mais significativas. Estas configurações visuais confirmam o que as investigadoras defendem: a crise humanitária acaba por ser uma crise da noção de responsabilidade.

A terceira tipologia de visibilidade mais usada é a da empatia, situação em que os refugiados são representados como vítimas que merecem preocupação e a denúncia dos casos de violação de direitos humanos, mas, mesmo assim, são números inferiores a 10\%.

\section{Conclusão}

A crise dos refugiados prossegue agora a um ritmo mais lento e contido. Mais distante da lente mediática em 2015, mas omnipresente nas tendências políticas anti-imigração e nas decisões estatais que decidem o encerramento de portos do Mediterrâneo. Por sua vez, o jornalismo, enquanto mediador e porta-voz, restringiu o seu papel à medida que reduziu a investigação.

Em 2019, para os média portugueses em foco, o refugiado é uma entidade sem voz e sem identidade. Não lhe é dado valor enquanto fonte das notícias publicadas, pois que não é, sequer, ouvido. Quando é representado, fazem-no sem individualização, como uma imagem padrão (ex. a "massa humana" num bote) que é replicada desde 2015 até hoje.

A definição de refugiado (a essência da sua situação) é ignorada, sem a devida contextualização deste universo para uma maior compreensão do leitor. É ausente de todas as notícias de 2019, o que nos diz que a cobertura jornalística continua a não ter em consideração a explicação dos conceitos, em particular deste conceito basilar, apesar do tempo decorrido entre o início da crise, em 2015, até à presente análise, de 2019.

O refugiado também não tem memória nos média, pois as peças sobre estes estão cada vez mais dispersas nas várias secções dos jornais, perdendo autonomia, e tornando-se mais difíceis de encontrar. Juntos, promovem o afastamento do público em relação ao tema. 
Chegados a 2019, o refugiado não foi preocupação dos média, que se limitaram, na grande maioria, à replicação dos conteúdos de agências noticiosas. No género predominante, a notícia, a visão ocidental tornou-se ainda mais acentuada, deixando para o refugiado o papel do outro. Aquele que, sem voz, sem identidade, sem contexto nem memória, não merece destaque na agenda mediática.

\section{REFERÊNCIAS}

Abdo, C., Cabecinhas, R. \& Brites, M. J. (2019). Crise migratória na Europa: os média e a construção da imagem dos refugiados. In Z. Pinto-Coelho; S. Marinho \& T. Ruão (Eds.), Comunidades, participação e regulação. VI Jornadas Doutorais, Comunicação Q Estudos Culturais (pp. 71-83). Braga: CECS.

ACNUR, Alto Comissariado das Nações Unidas para os Refugiados. (2019). Global trends report. Forced displacement in 2018. Retirado de https://www.unhcr.org/globaltrends2018/

Blumell, L. E., Bunce, M., Cooper, G. \& McDowell, C. (2020). Refugee and asylum news coverage in UK print and online media. Journalism Studies, 21(2), 162-179. https://doi.org/10.1080/1461670X.2019.1633243

Chaíça, I. (2019, o3 de janeiro). Morreram 2262 refugiados no mar Mediterrâneo em 2018. Público. Retirado de https://www.publico.pt/2019/01/03/mundo/noticia/migrantes-mediterraneo-europa-1856539

Chouliaraki, L. \& Stolic, T. (2017). Rethinking media responsibility in the refugee "crisis": a visual typology of European news. Media, Culture and Society, 39(8), 1162-1177. https://doi.org/10.1177/0163443717726163

ONU, Organização das Nações Unidas. (1948). Declaração Universal dos Direitos Humanos. Retirado de https://nacoesunidas.org/wp-content/uploads/2018/10/DUDH.pdf

ONU, Organização das Nações Unidas. (1951). Convenção das Nações Unidas relativa ao estatuto dos refugiados. Retirado de http://www.acnur.org/t3/fileadmin/Documentos/portugues/BDL/Convencao_ relativa_ao_Estatuto_dos_Refugiados.pdf

Empinotti, M. (2017). Discriminação no discurso: análise da representação de refugiados no Público através da gramática visual de Kress e Van Leeuwn. Media@Journalism, 17(31), 95-116.

Fernando, R. (2019, 19 de junho). Refugiados são já mais de 70 milhões, número recorde. Público. Retirado de https://www.publico.pt/2019/06/19/mundo/noticia/ refugiados-sao-ja-70-milhoes-recorde-20-anos-1876916

Gemi, E., Ulasiuk, I. \& Triandafyllidou, A. (2013). Migrants and media newsmaking practices. Journalism Practice, 7(3), 266-281.

Guerreiro, D. (2018). A crise dos refugiados no Mediterrâneo - a cobertura jornalística em Portugal e proposta de modelo editorial. Tese de Mestrado, Universidade Nova de Lisboa, Lisboa, Portugal. Retirado de https:// run.unl.pt/handle/10362/46729

Hafez, K. (2009, março). Global journalism for global governance? Theoretical visions, practical constraints. Comunicação apresentada no congresso Power and Pluralism. A Media Seminar on International Reporting, Suécia.

Jodelet, D. (1989). Les représentations sociales. Paris: Presses Universitaires de France.

Kovach, B. \& Rosenstiel, T. (2001). Os elementos do jornalismo. Porto: Porto Editora. 
Martins, M. L. (2019). A “crise dos refugiados” na Europa - entre totalidade e infinito. Comunicação $e$ Sociedade, [Vol. especial], 21-36. https://doi.org/10.17231/comsoc.0(2019).3058

McIntyre, P. (2003). Human rights reporting - a handbook for journalists in Southeastern Europe. International Federation of Journalists and European Commission. Retirado de http://www.ifj.org/nc/news-single-view/backpid/59/category/reports-1/article/ journalism-and-human-rights-handbook-on-human-rights-reporting-in-southeastern-europe-2003/

Moscovici, S. (1961/2003). Representações sociais: investigações em Psicologia Social. Petrópolis: Vozes.

Obercom. (2003). Representações (imagens) dos imigrantes e das minorias étnicas na imprensa. Retirado de https://www.om.acm.gov.pt/documents/58428/177157/Estudo+Obercom.pdf/ a664dc38-65cf-4398-896a-751dbddeoc5a

OIM, Organização Internacional para as Migrações. (2019). World migration report 2020. Genebra.

Pöyhtäri, R. (2014). Immigration and ethnic diversity in Finnish and Dutch magazines: articulations of subject positions and symbolic communities. Tese de Doutoramento, Tampere University, Tampere.

Rose, T. (2013). A human rights-based approach to journalism: Ghana. The Journal of International Communication, 19(1), 85-106.

Shaw, I. S. (2012). Human rights journalism: advances in reporting distant humanitarian interventions. Bakingstoke, Hampshire: Palgrave Macmillan.

Silvestre, F. (2011). Um olhar sobre a imprensa: representações sobre os requerentes de asilo e refugiados em Portugal. Dissertação de Mestrado, Universidade Nova de Lisboa, Lisboa, Portugal.

The International Council Human Rights Policy. (2002). Journalism, media and the challenges of human rights reporting. Retirado http://www.ichrp.org/files/reports/14/106_report_en.pdf

Thompson, A. (2007). The responsibility to report: a new journalistic paradigm. In A. Thompson (Ed.), The media and the Rwanda Genocide (pp. 433-445). Londres: Pluto Press.

\section{NOTAS BIOGRÁFICAS}

Dora Santos-Silva é Professora Auxiliar no Departamento de Ciências da Comunicação da Faculdade de Ciências Sociais e Humanas da Universidade Nova de Lisboa, onde concluiu a licenciatura em Ciências da Comunicação, o mestrado em Cultura Contemporânea e Novas Tecnologias, e o doutoramento em Digital Media (programa UT Austin Portugal).

ORCID: https://orcid.org/0000-0003-1611-8858

Email: dorasantossilva@fcsh.unl.pt

Morada: NOVA FCSH, Avenida de Berna, 26-C, 1069-061 Lisboa

Débora Guerreiro é licenciada em Direito pela Faculdade de Direito da Universidade de Lisboa e mestre em Jornalismo pela Faculdade de Ciências Sociais e Humanas da Universidade Nova de Lisboa.

ORCID: https://orcid.org/0000-0003-1708-4047 
Email: debora.santos.guerreiro@gmail.com

Morada: NOVA FCSH, Avenida de Berna, 26-C, 1069-061 Lisboa

Submetido: 15/04/2020

Aceite: 13/05/2020 